\title{
An Iridium-SPO Complex as Bifunctional Catalyst for the Highly Selective Hydrogenation of Aldehydes $\dagger$
}

\author{
Israel Cano, ${ }^{* a b}$ Luis M. Martínez-Prieto, ${ }^{a}$ Laure Vendier, ${ }^{\mathrm{c}}$ and Piet W. N. M. van \\ Leeuwen*a
}

\begin{abstract}
A secondary phosphine oxide (SPO) ligand (tert-butyl(phenyl)phosphine oxide) was employed to generate an Ir-SPO complex which shows a particular ability to activate dihydrogen under mild conditions without the help of an external base or additive. Such an iridium (I) complex serves as a precursor for homogeneous catalysis since under $\mathrm{H}_{2}$ it is converted to a mixture of several iridium (III) hydride species that are the active catalysts. This system was found to be a highly active catalyst for the hydrogenation of substituted aldehydes, giving very high conversions and chemoselectivities for a wide range of substrates. The SPO ligand presumably plays a key role in the catalytic process through heterolytic cleavage of $\mathrm{H}_{2}$ by metal-ligand cooperation. In addition, an exhaustive characterization of the different iridium hydride species was performed by 1D and 2D NMR spectroscopy. The oxidative addition of $\mathrm{H}_{2}$ to the $\operatorname{Ir}(\mathrm{I})-\mathrm{SPO}$ complex is highly stereoselective, as all generated $\operatorname{Ir}(\mathrm{III})$ hydrides are homochiral. Finally, the crystal structure, as determined by X-Ray Diffraction, of a dinuclear iridium (III) hydride complex is described.
\end{abstract}

\section{INTRODUCTION}

The selective hydrogenation of an aldehyde function in the presence of other reducible groups is an important step in synthetic chemistry. As an example, the chemoselective reduction of $\alpha, \beta$ unsaturated aldehydes to their corresponding allylic alcohols has tremendous industrial importance, since these compounds are relevant intermediates and end products in the preparation of fine chemicals, flagrances and pharmaceutical compounds. ${ }^{1}$ An interesting pathway to reduce polarized $\mathrm{C}=\mathrm{X}$ bonds is the heterolytic cleavage of dihydrogen into $\mathrm{H}^{+}$and $\mathrm{H}^{-}$ , and the subsequent transfer of hydrogen atoms to substrates such as $\mathrm{C}=\mathrm{O}$ bonds. ${ }^{2}$ In this

\footnotetext{
a Laboratoire de Physique et Chimie des Nano Objets, LPCNO, UMR5215 INSA-UPS-CNRS, Institut National des Sciences Appliquées, 135 Avenue de Rangueil, 31077 Toulouse, France

${ }^{\mathrm{b}}$ GSK Carbon Neutral Laboratory for Sustainable Chemistry, University of Nottingham, NG7 2GA, Nottingham, UK

c CNRS, LCC (Laboratoire de Chimie de Coordination) 205 Route de Narbonne, BP44099, F-31077 Toulouse Cedex 04, France; Université de Toulouse, UPS, INPT, F-31077 Toulouse Cedex 04, France

$\dagger$ Electronic supplementary information (ESI) available: Synthesis, experimental procedure and supporting data.
} 
approach $\mathrm{H}_{2}$ is frequently cleaved by metal-ligand cooperation; that is, a ligand containing basic sites and a coordinated metal center operate in tandem to activate the hydrogen molecule. ${ }^{3}$

In the field of homogeneous catalysis, this type of process is accomplished by numerous transition metal complexes, leading to the hydrogenation of aldehydes, ketones, and imines. ${ }^{4}$ However, iridium-based complexes have shown a limited efficiency in the chemoselective hydrogenation of substituted aldehydes and only a few systems performing this transformation have been reported in the literature. ${ }^{5,6}$ Additionally, some of these complexes are not able to act as bifunctional catalysts and require the help of an external base to promote the heterolytic splitting of $\mathrm{H}_{2} \cdot{ }^{5, \mathrm{i}}$ On the other hand, in the area of metallic nanoparticle (MNP) catalysis, this process is rarely achieved by a heterolytic cleavage mechanism involving the ligand or stabilizing agent. Indeed, the described systems based on iridium produce the $\mathrm{H}_{2}$ activation and its later transfer to aldehydes by the use of heterogeneous catalysts consisting of iridium nanoparticles (IrNPs) immobilized on oxide supports or oxygenated surfaces, ${ }^{7}$ for which the process takes place by a strong metal-support interaction. ${ }^{8}$

Along this line, secondary phosphine oxides (SPOs) form an interesting group of phosphorus ligands. ${ }^{9}$ Once coordinated (via P) as the phosphinous(III) tautomer ${ }^{10}$ to a suitable transition metal, the resulting complexes display an ability to cleave $\mathrm{H}_{2}$ heterolytically across $\mathrm{M}$ and $\mathrm{O}$, as long as there is a vacancy on the metal. Then, the complex can transfer the hydrogen atoms to an appropriate substrate. ${ }^{11}$ This SPO-metal cooperative effect has been widely utilized in hydrogenation catalysis, in which such reactivity is particularly notorious. ${ }^{12}$ In that regard, our group has a longstanding experience in the use of this type of ligands, both in homogeneous ${ }^{11}$ and $\mathrm{MNP}^{13}$ catalysis.

Inspired by these works, we recently reported the synthesis and characterization of an Ir-SPO complex, for which two coordinated phosphine oxide ligands self-assemble after loss of one proton into a monoanionic bidentate ligand held together by an intramolecular hydrogen bond. ${ }^{14}$ In a preliminary catalytic study, the system showed a very high activity and selectivity in the chemoselective hydrogenation of cinnamaldehyde and $p$-nitrobenzaldehyde. The complex acts as precursor for homogeneous catalysis, since under $\mathrm{H}_{2}$ it is converted to a mixture of several hydrides.

Herein we describe the characterization and catalytic applications of such an Ir-SPO hydride system. This catalyst is very active for the chemoselective hydrogenation of substituted aldehydes, providing exceptionally high conversions and selectivities. The SPO ligand presumably plays a crucial double role, as modifying ligand, and as functional ligand acting as heterolytic activator for dihydrogen, since its oxygen atom operates as a basic site and takes a $\mathrm{H}^{+}$from $\mathrm{H}_{2}$, leaving a $\mathrm{H}^{-}$bound to the metal center. ${ }^{11,13}$ 


\section{RESULTS AND DISCUSSION}

\section{Synthesis and Characterization of Catalytic System}

Treatment of (1,5-cyclooctadiene)(methoxy)iridium(I) dimer $\left([\operatorname{Ir}(\mathrm{OMe})(\mathrm{COD})]_{2}\right)$ with 4 equivalents of tert-butyl(phenyl)phosphine oxide (1) and 2 equivalents of $\mathrm{H}_{2} \mathrm{O}$ affords complex 2 (Scheme 1, for further details see $\mathrm{ESI} \uparrow) .{ }^{14}$

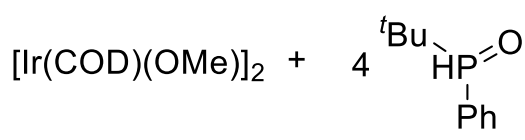

1

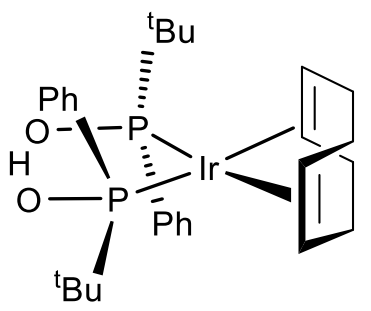

2

Scheme 1 Formation of iridium SPO complex 2.

The structure of $\mathbf{2}$ was elucidated unambiguously by single crystal X-ray structure analysis and solid state fast magic angle spinning (MAS) ${ }^{1} \mathrm{H}$ NMR. ${ }^{14}$ Complex 2 adopts a square planar molecular geometry around the metal center with double coordination to cyclooctadiene (COD) and the SPO ligands coordinated to the iridium center as a hydrogen bonded pair of the two, for which SPOs have a strong preference in metal complexes thus obtaining a monoanionic bidentate ligand. ${ }^{15}$

This complex is a precursor instead of an active catalyst for aldehyde hydrogenation. To investigate the active catalytic species, we treated iridium complex 2 with 5 bar of $\mathrm{H}_{2}$ pressure in acetonitrile (AN) at room temperature (R.T.) for $30 \mathrm{~min}$ (Scheme 2, for further details see ESI†). 

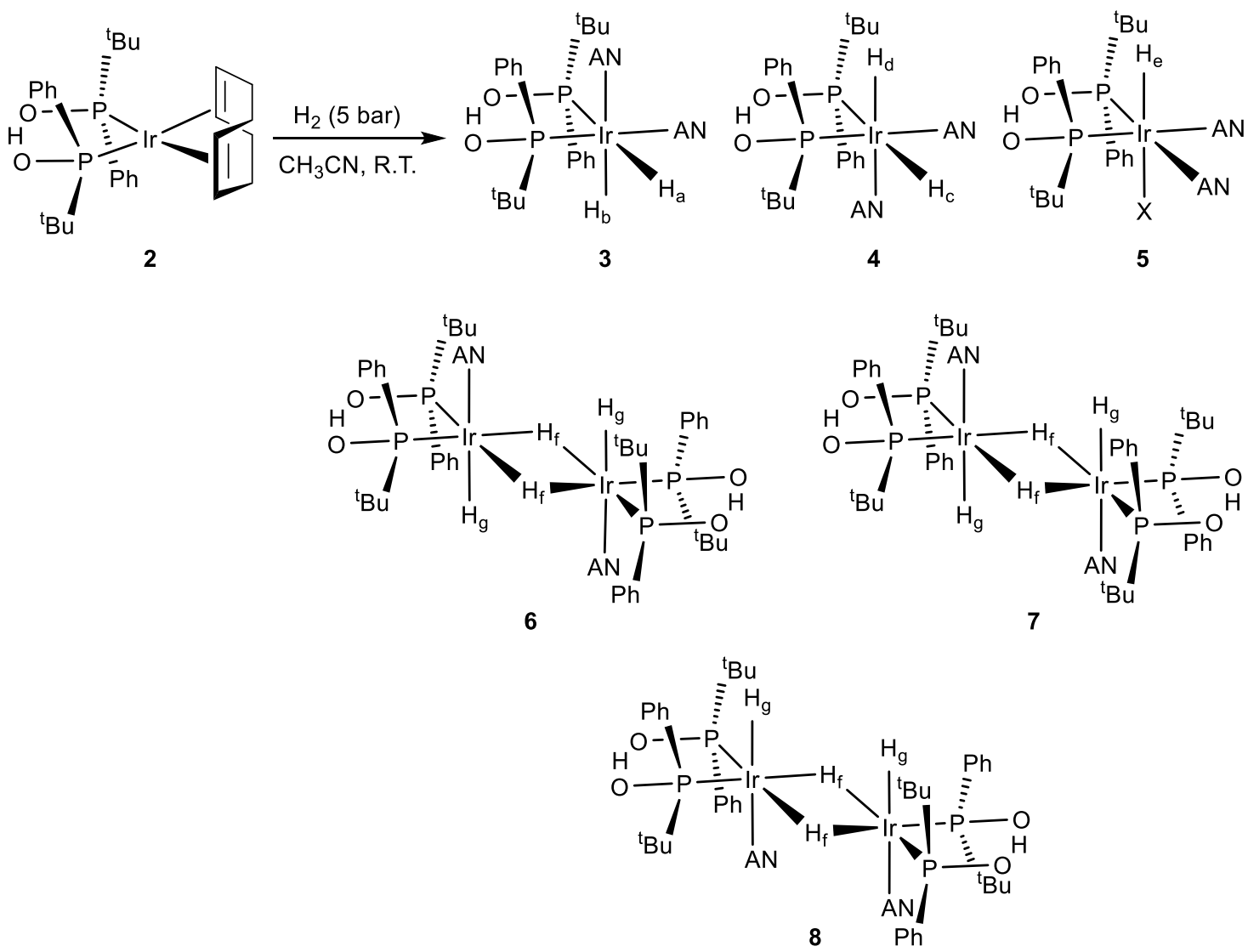

Scheme 2. Formation of Iridium (III) hydride species under substrate-free hydrogenation conditions.

Under $\mathrm{H}_{2}$, the $\operatorname{Ir}(\mathrm{I})$ complex is converted, via $\mathrm{H}_{2}$ oxidative addition, to a mixture of one monohydride $\operatorname{Ir}\left((\mathrm{SPO})_{2} \mathrm{H}\right) \mathrm{H}(\text { solvent })_{2} \mathrm{X} \quad$ (5), two diastereomeric dihydrides $\operatorname{Ir}\left((\mathrm{SPO})_{2} \mathrm{H}\right) \mathrm{H}_{2}$ (solvent $)_{2}(\mathbf{3}, \mathbf{4})$ and three bridging dihydride dimers $(\mathbf{6}-\mathbf{8})$ thereof after loss of a solvent molecule (Scheme 2). The reaction is very fast with an instantaneous change of colour from red-orange to light yellow. The NMR analyses in tetrahydrofuran $\left(\mathrm{THF}-\mathrm{d}^{8}\right)$ led to rapid decomposition and therefore we conducted the experiments in acetonitrile $\left(\mathrm{CD}_{3} \mathrm{CN}\right)$, which has a stabilizing effect on the hydrides. ${ }^{16}$

The oxidative addition of $\mathrm{H}_{2}$ to $\operatorname{Ir}(\mathrm{I})$ complex 2 was studied by ${ }^{1} \mathrm{H}$ and ${ }^{31} \mathrm{P}$ NMR spectroscopy. The hydride region of the ${ }^{1} \mathrm{H}$ NMR spectrum acquired $30 \mathrm{~min}$ after introducing $\mathrm{H}_{2}$ into the solution shows several iridium dihydride species (Fig. 1). The hydride resonances with highest intensity correspond to diastereomer $\mathbf{3}$ and appear as a double doublet of doublets at -10.38 ppm $\left(\mathrm{H}_{\mathrm{a}}\right)$ due to cis and trans phosphorus couplings (19.1 and $143.3 \mathrm{~Hz}$, respectively) and one hydrogen coupling $(4.8 \mathrm{~Hz})$, and as a double doublet of doublets at $-21.40 \mathrm{ppm}\left(\mathrm{H}_{\mathrm{b}}\right)$ attributable to the coupling with two cis phosphorus $(14.5$ and $20.7 \mathrm{~Hz})$ and one hydrogen $(4.8 \mathrm{~Hz})$. Similarly, the hydride resonances for the minor diastereomer $\mathbf{4}$ appear as a couple of double doublet of doublets at $-9.77 \mathrm{ppm}\left(\mathrm{H}_{\mathrm{c}}, J_{\mathrm{P}-\mathrm{H}}=140.9,19.8 \mathrm{~Hz}\right.$ and $\left.J_{\mathrm{H}-\mathrm{H}}=4.8 \mathrm{~Hz}\right)$ and $-21.52 \mathrm{ppm}$ 
$\left(\mathrm{H}_{\mathrm{d}}, J_{\mathrm{P}-\mathrm{H}}=22.7,12.6 \mathrm{~Hz}\right.$ and $\left.J_{\mathrm{H}-\mathrm{H}}=4.8 \mathrm{~Hz}\right)$, since both diastereomers exhibit the same coordination geometries. ${ }^{17}$ The ratio between the diastereomers is 2.23:1.

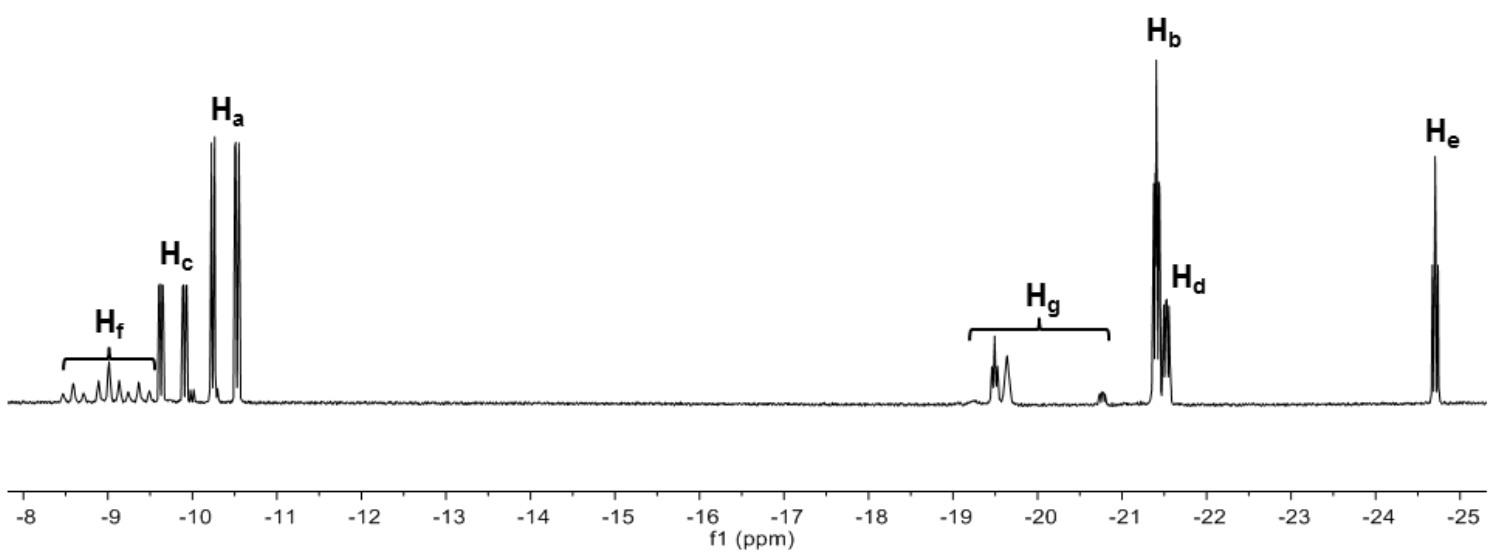

Fig. $1{ }^{1} \mathrm{H}$ NMR spectrum (500 MHz) in the hydride region after reaction of 2 with $\mathrm{H}_{2}$ (5 bar) in $\mathrm{CD}_{3} \mathrm{CN}$.

The identity of the major diastereomer $\mathbf{3}$ was established by 2D NOESY NMR experiments (Fig. S3†). As the tert-butyl groups are non-equivalent, both diastereomers display 2 signals for these substituents in the ${ }^{1} \mathrm{H}$ NMR spectrum (Fig. S2 $\dagger$ ), being the most intense peaks those that belong to $3(0.71$ and $0.94 \mathrm{ppm})$. Only the tert-butyl group at $0.71 \mathrm{ppm}$ shows NOESY correlations with both hydrides $\mathrm{H}_{\mathrm{a}}$ and $\mathrm{H}_{\mathrm{b}}$ (Fig. S3 $\dagger$ ) in this species, whereas the other tert-butyl substituent does not give signal with the axial hydride $\mathrm{H}_{\mathrm{b}}$. This suggests that the tert-butyl groups of $\mathbf{3}$ are placed in trans position. Indeed, no interaction between the tert-butyl groups of 3 was detected in the NOESY experiment (Fig. S4 $\dagger$ ). In addition, the tert-butyl resonances for 4 appear at 0.80 and $0.82 \mathrm{ppm}$ (Fig. S2 $\dagger$ ). The ${ }^{31} \mathrm{P}\{\mathrm{H}\}$ NMR spectrum (Fig. S5 $\dagger$ ) exhibits two doublet signals for each diastereomer $\left(70.2\right.$ and $77.2 \mathrm{ppm}$ with $J_{\mathrm{P}-\mathrm{P}}=14.6 \mathrm{~Hz}$ for $\mathbf{3}$, and 62.5 and $84.2 \mathrm{ppm}$ with $J_{\mathrm{P}-\mathrm{P}}=14.9 \mathrm{~Hz}$ for $\mathbf{4}$ ). The assignation of signals was performed through a ${ }^{1} \mathrm{H}-{ }^{31} \mathrm{P}$ HMBC $2 \mathrm{D}$ experiment (Fig. S6† and S7†), which also enabled us to confirm the identity of the tert-butyl resonances corresponding to $\mathbf{4}$. Both iridium dihydride complexes $\mathbf{3}$ and $\mathbf{4}$ are homochiral (Scheme 2 shows the $R R$ isomers), which is the most stable configuration, and there is no meso isomer.

The ${ }^{1} \mathrm{H}$ NMR spectrum in the hydride region also shows a signal attributable to a species $\mathbf{5}$ with one hydride $\left(\mathrm{H}_{\mathrm{e}}\right)$ and one non-identified anion $(\mathrm{X})$ generated by decomposition, both located in axial position (Scheme 2). The hydride resonance appears at $-24.70 \mathrm{ppm}$ as a well-resolved triplet with $J_{\mathrm{P}-\mathrm{H}}$ of $13.6 \mathrm{~Hz}$ (Fig. 1) due to the coupling with two cis phosphorus nuclei (the signal would be located at $-5-(-10) \mathrm{ppm}$ in case of coupling with one trans phosphorus nucleus $)$, whereas the phosphorus signals arise as two doublets (AB pattern) at $77.6\left(J_{\mathrm{P}-\mathrm{P}}=12.7\right.$ 
$\mathrm{Hz})$ and $78.1 \mathrm{ppm}\left(J_{\mathrm{P}-\mathrm{P}}=13.2 \mathrm{~Hz}\right)$ in the ${ }^{31} \mathrm{P}\{\mathrm{H}\}$ NMR spectrum (Fig. S5 $†$ and S6 $†$ ). This $\mathrm{AB}$ system indicates that the molecule is homochiral $(R R / S S)$, since a meso compound would give a singlet signal for the two phosphorus in the ${ }^{31} \mathrm{P}\left\{{ }^{1} \mathrm{H}\right\}$ NMR spectrum. The integration of hydride signals in the ${ }^{1} \mathrm{H}$ NMR spectrum reveals that the iridium monohydride complex is the third most abundant species. Consequently, the peaks for the tert-butyl substituents are those observable at 0.64 and $0.97 \mathrm{ppm}$ in the ${ }^{1} \mathrm{H}$ NMR spectrum, which was corroborated by analysis of the ${ }^{1} \mathrm{H}-{ }^{31} \mathrm{P}$ HMBC 2D experiment in the tert-butyl zone (Fig. S7†).

On the other hand, we observed the formation of three dimers 6,7 and 8 with bridging and terminal hydrides as minor species (Scheme 2 and Fig. 1). The hydride region of the ${ }^{1} \mathrm{H}$ NMR spectrum displays three triplets at $\delta-8.59\left(J_{\mathrm{P}-\mathrm{H}}=60.5 \mathrm{~Hz}\right),-9.01\left(J_{\mathrm{P}-\mathrm{H}}=61.5 \mathrm{~Hz}\right)$ and -9.37 $\operatorname{ppm}\left(J_{\mathrm{P}-\mathrm{H}}=62.3 \mathrm{~Hz}\right)$ corresponding to the bridging hydrides $\left(\mathrm{H}_{\mathrm{f}}\right)$ of each dimer, and small signals around -19.5 and $-20.8 \mathrm{ppm}$ attributable to the terminal hydrides $\left(\mathrm{H}_{\mathrm{g}}\right){ }^{18}$ Each dimeric species exhibits two different phosphorus environments, giving a pair of signals in the ${ }^{31} \mathrm{P}\{\mathrm{H}\}$ NMR spectrum (Fig. S5 $†$ ). As was previously described for the mononuclear iridium complexes 3-5, all the dimers are homochiral and there are no meso isomers because all the dimeric species generate two peaks with cis phosphorus coupling in the ${ }^{31} \mathrm{P}\{\mathrm{H}\}$ NMR spectrum (Fig. S5 $\dagger$ ). The homochiral nature of all species as caused by the bulky tert-butyl groups reduces the number of possible diastereoisomers and allows the present interpretation.

Evaporation of solvent favors a displacement of the equilibrium between the hydride species toward the formation of the dimers. As a result, crystals of the dinuclear iridium(III) hydride complex 7 suitable for X-ray Diffraction were obtained. The crystal structure of $\mathbf{7}$ is shown in Figure 2. The Ir-Ir distance is $2.77 \AA$, in good agreement with the values reported in the literature for dinuclear $\operatorname{Ir}(\mathrm{III}) / \mathrm{Ir}(\mathrm{III})$ complexes containing an $(\mathrm{IrH})_{2}\left(\mu-\mathrm{H}_{2}\right)$ unit. $^{16,18,19}$ The $\operatorname{Ir}_{2}$ core possesses a 36-electron configuration with no $\mathrm{M}-\mathrm{M}$ bond. The two acetonitrile molecules are orientated mutually trans. However, the two terminal hydrides were not located by Fourier differences, but one vacant site in the coordination sphere of each iridium atom trans to the acetonitrile molecule were assumed to be their positions. Fourier differences revealed a Ir1-Hy2 distance of $1.75 \AA$ and an Ir1-Ir $1^{\mathrm{i}}$-Hy 2 angle of $42.9^{\circ}$, the latter very close to the $45^{\circ}$ required for the bridging hydrides being equidistant to both iridium atoms. Interestingly, Fourier differences also showed that the intramolecular hydrogen bond $\mathrm{O}-\mathrm{H}-\mathrm{O}$ contained in the monoanionic bidentate ligand is essentially linear (O...O is $2.398 \AA$ ) as was also found by DFT calculations for related Rh complexes, ${ }^{11 \mathrm{e}}$ and as was already proposed by Palenik et al. on the basis of the short O.... distance of $2.5 \AA$ in Pd-SPO complexes, ${ }^{20}$ although routinely the structures are drawn showing the $\mathrm{O}-\mathrm{H}-\mathrm{O}$ atoms as part of a regular 6-membered ring. ${ }^{1 \mathrm{a}-\mathrm{d}}$ 


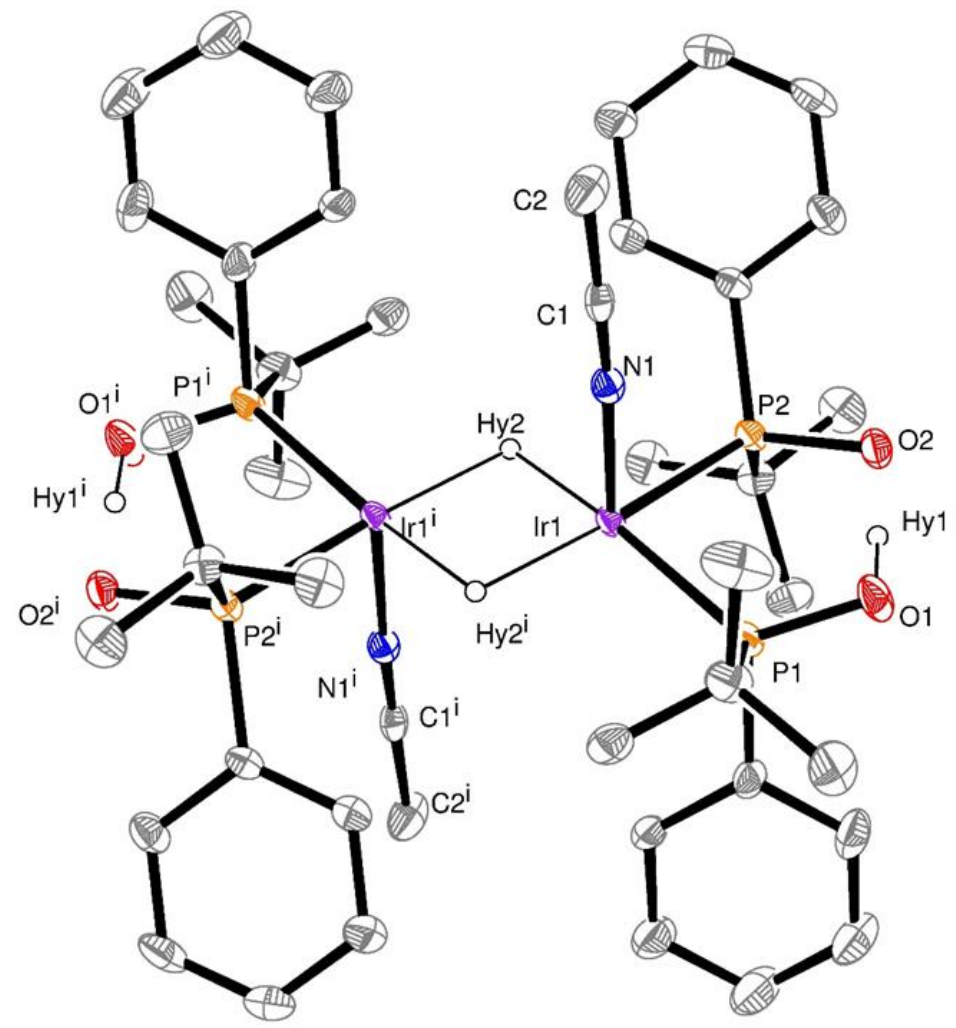

Fig. 2 X-ray structure of 7 showing thermal ellipsoids set at $40 \%$ probability level. Selected bond lengths ( $)$ : Ir1-P1, 2.2930(13); Ir1-P2, 2.2794(12); Ir1-N1, 2.120(4); Ir1-Hy2, 1.75(6); $\mathrm{P} 1-\mathrm{O} 1,1.555(4) ; \mathrm{P} 2-\mathrm{O} 2,1.558(4) ; \mathrm{O} 1-\mathrm{Hy} 1,0.97(6) ; \mathrm{O} 2-\mathrm{Hy} 1,1.43(6)$. Selected angles (deg): N1-Ir1-P2, 91.61(11); N1-Ir1-Hy2, 89(2); P2-Ir1-P1, 89.01(5); P2-Ir1-Hy2, 90.3(19).

As concerns the symmetry, the crystal structure of $\mathbf{7}$ contains an inversion center but has neither a plane of symmetry (due to the chiral ligands) nor a 2 -fold axis due to the acetonitrile molecules and hydrides in trans axial positions. The tert-butyl groups are placed in trans position and the pairs of SPOs exhibit an $R$ configuration at the phosphorus atoms in one monoanionic bidentate ligand and $S$ in the other one. Thus, one side of the dimer is $R R$ and the other side is $S S$, giving two doublets at approximately $72\left(J_{\mathrm{P}-\mathrm{P}}=\sim 22 \mathrm{~Hz}\right)$ and $\sim 82 \mathrm{ppm}\left(J_{\mathrm{P}-\mathrm{P}}=\right.$ $\sim 22 \mathrm{~Hz}$ ) in the ${ }^{31} \mathrm{P}\left\{{ }^{1} \mathrm{H}\right\}$ NMR spectrum (Fig. S5 $\dagger$ ).

\section{Catalytic Hydrogenation of Substituted Aldehydes}

This encouraging demonstration of hydrogen activation prompted us to evaluate the ability of the Ir-SPO system as hydrogenation catalyst. The hydrogenation of a range of substituted aldehydes was investigated using catalytic quantities of $\mathbf{2}$, which was found to be the precursor for a highly active and almost exclusively selective catalyst. Firstly, we decided to evaluate the activity of the catalytic system in a screening set of experiments for the hydrogenation reaction of cinnamaldehyde (Table 1). At R.T. and 5 bar $\mathrm{H}_{2}$ pressure, complete selectivity toward the unsaturated alcohol was observed in $1 \mathrm{~h}$, albeit with low conversion (entry 1, 25\%). In $2.5 \mathrm{~h}$, 
97\% conversion and 99\% selectivity to the expected allylic alcohol were obtained (entry 2). Increasing the time to $4.5 \mathrm{~h}$, quantitative conversion of the substrate with $>99 \%$ selectivity was achieved (entry 4). With the pressure maintained at 5 bar but increasing the temperature to 60 ${ }^{\circ} \mathrm{C}$, a decrease in the conversion was observed (entry 11, 45\%), which points to some decomposition and/or deactivation process of the catalyst. Furthermore, a loss of selectivity to the $\alpha, \beta$-unsaturated alcohol was produced. We observed hydrogenation of the $\mathrm{C}=\mathrm{C}$ bond and both 3-phenylpropanal (6\%) and 3-phenylpropanol (4\%) were generated in addition to the expected product (cinnamyl alcohol, 90\%). The solvent was found to be relatively important in that THF consistently provided good results (entry 2-5), while other solvents gave much lower conversions (entry 6, toluene; entry 7, $\mathrm{CH}_{2} \mathrm{Cl}_{2}$ ). Moreover, the use of methanol led to a decrease in the selectivity, since the acetal derivative was generated as by-product (entry 8).

It is worth noting that the use of higher pressures or longer reaction times involved only a slight reduction in the chemoselectivity (entries 5,9 and 10), which highlights the preference of the catalytic system toward the aldehyde functionality. With these optimized reaction parameters based on $2.5 \mathrm{~h}$ as reaction time, R.T., 5 bar of hydrogen pressure and THF as solvent, a TON of 2910 and a TOF of $1164 \mathrm{~h}^{-1}$ (entry 2 ) were achieved.

Table 1 Optimization Parameters for the Hydrogenation of Cinnamaldehyde. ${ }^{a}$

\begin{tabular}{|c|c|c|c|c|c|c|}
\hline Entry & Solvent & $\mathbf{T}(\mathbf{K})$ & Time (h) & $\mathbf{P}($ bar $)$ & Conversion $(\%)^{b}$ & Selectivity $(\%)^{c}$ \\
\hline 1 & THF & 295 & 1 & 5 & 25 & $>99$ \\
\hline 2 & THF & 295 & 2.5 & 5 & 97 & 99:1 (UA:A) \\
\hline 3 & THF & 295 & 3 & 5 & 99 & 99:1 (UA:Al+A) \\
\hline 4 & THF & 295 & 4.5 & 5 & $>99$ & $>99$ \\
\hline 5 & THF & 295 & 5 & 5 & $>99$ & 99:1 (UA:A) \\
\hline 6 & Toluene & 295 & 4.5 & 5 & 2 & $>99$ \\
\hline 7 & $\mathrm{CH}_{2} \mathrm{Cl}_{2}$ & 295 & 4.5 & 5 & 4 & $>99$ \\
\hline 8 & $\mathrm{CH}_{3} \mathrm{OH}$ & 295 & 4.5 & 5 & 50 & $56^{d}$ \\
\hline 9 & THF & 295 & 18 & 5 & $>99$ & 96:4 (UA:A) \\
\hline 10 & THF & 295 & 18 & 10 & $>99$ & 98:2 (UA:A) \\
\hline 11 & THF & 333 & 4.5 & 5 & 45 & 90:6:4 (UA:Al:A) \\
\hline
\end{tabular}

$\bar{a}$ Reagents and conditions: $2(0.00125 \mathrm{mmol})$, cinnamaldehyde $(3.75 \mathrm{mmol})$, solvent $(0.75 \mathrm{~mL}){ }^{b}$ Conversions determined by ${ }^{1} \mathrm{H}$ NMR spectroscopy and refer to the selective conversion of cinnamaldehyde (average of two runs). ${ }^{c} U A=$ Unsaturated Alcohol, $A=$ Saturated Alcohol, $A l$ $=$ Saturated Aldehyde. ${ }^{d}$ The formation of the acetal product was observed. 
We studied the rate dependence on the reaction time (Fig. 3). The profile clearly shows an incubation time of $c a .1 \mathrm{~h}$, during which 2 generates the catalytically active hydrides species. Since the hydrides are formed in acetonitrile on the timescale of the NMR sample preparation, we cannot say what this incubation time involves. Nanoparticle formation can be excluded on the basis of rate -IrNP being $>50$ times slower catalysts for entry 1 - and selectivity, vide infra. ${ }^{14}$ Indeed, the formation of nanoparticles requires more than $12 \mathrm{~h}$ under 5 bar of $\mathrm{H}_{2}$ pressure, whereas no nanoparticles generation was observed under these conditions in the NMR tube employed for the characterization of hydrides. ${ }^{14}$ From the profile we deduced a maximum TOF of $2040 \mathrm{~h}^{-1}$ at $1.5-2 \mathrm{~h}$ of reaction for the hydrogenation of cinnamaldehyde. To the best of our knowledge, the catalytic system described herein performs as one of the best catalysts in terms of rate and selectivity compared to iridium-based systems reported to date. ${ }^{5,7}$ The oxidative addition of $\mathrm{H}_{2}$ observed is the same as that described for diphosphine complexes ${ }^{17}$ and thus there is no indication that in this instance we are dealing with a heterolytic cleavage. ${ }^{21}$ Since the present Ir-SPO catalyst shows poor activity for alkenes compared to iridium catalysts containing neutral ligands (monophosphines, bisphosphines, Phox ligands), mechanistically the SPO function might be involved in the hydrogenation, but firm evidence is lacking.

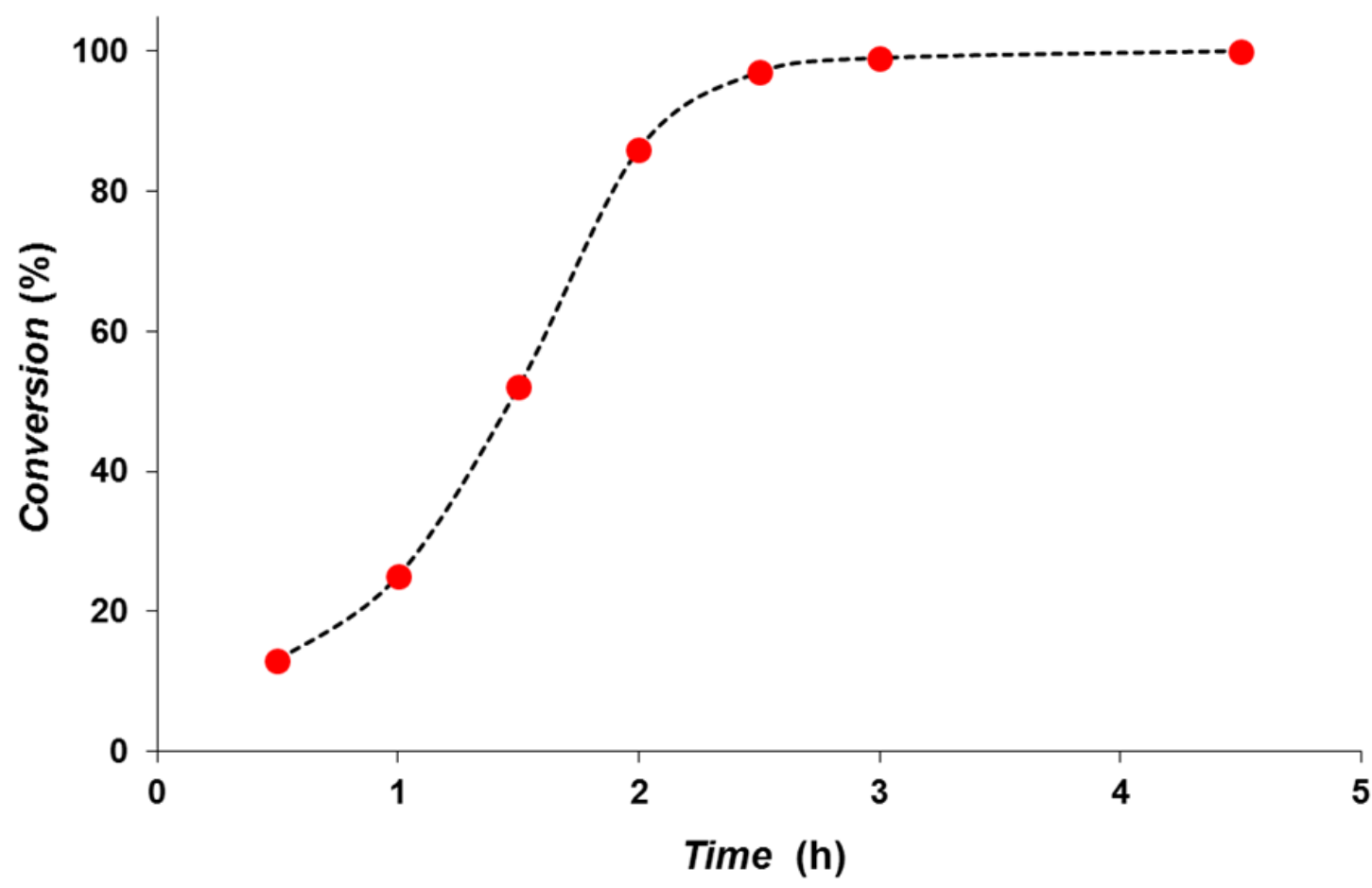

Fig. 3 Profile of the evolution of the reaction with the time for the hydrogenation of cinnamaldehyde. Reagents and conditions: 2 (0.00125 mmol), cinnamaldehyde $(3.75 \mathrm{mmol})$, THF (0.75 mL), 5 bar, $295 \mathrm{~K}$. 
With optimized conditions in hand, we were keen to study the substrate scope and functional groups tolerated by $\mathbf{2}$ (Table 2). The catalyst showed a very high activity and selectivity in the hydrogenation of aldehydes over other functional groups. In terms of activity, the reaction appears to be very general and, in nearly all cases, very high conversions were obtained. Nevertheless, we observed differences in the TOF depending on the reactant, since some substrates required longer reaction times to complete the catalytic process (Table 2 and Section $4 \dagger)$.

In all cases, high selectivities were observed for several $\alpha, \beta$-unsaturated aldehydes (entries $1-$ 4), including some that are of particular interest in the production of perfumes and fragrances. ${ }^{22}$ The complex was very selective to the carbonyl functionality in cinnamaldehyde and prenal (entries 1-2). However, a slight reduction in the selectivity was produced in the hydrogenation of trans-2-hexen-1-al in comparison with the previous substrates (entry 3). The steric impediment in the former probably avoids a higher reduction of the $\mathrm{C}=\mathrm{C}$ bond. Of particular importance is the selective hydrogenation of citral, which proceeded with complete chemoselectivity (entry 4). Interestingly, in contrast to other systems based on $\mathrm{Ru},{ }^{23}$ no reaction was observed in the reduction of 2-octynal. Indeed, this substrate poisoned the catalyst, as we reported in a preliminary communication. ${ }^{14}$

In addition to this selectivity to $\mathrm{C}=\mathrm{O}$ over alkenes, the catalyst is highly tolerant to several other functional groups. For example, the hydrogenation of $p$-nitrobenzaldehyde yielded the corresponding nitrobenzyl alcohol with perfect retention of the nitro group (entry 5). This is the second indication that nanoparticles are not responsible for the catalytic activity, because IrNPs gave formation of aminoaldehyde and aminoalcohol when used as the catalyst. ${ }^{14}$ In addition, we found poisoning of the catalytic system for the reactions with $p$-cyanobenzaldehyde and 2octynal, while IrNPs on the contrary showed high conversions and chemoselectivities in the hydrogenation of these substrates. ${ }^{14}$ Esters were also tolerated excellently and the aldehyde group was selectively reduced to alcohol (entry 6). Finally, complete chemoselectivity was observed in compounds containing reducible heteroaromatic substituents (entries 7-8), such as furfural (compound derived from biomass) and 2-thiophenecarboxaldehyde. 
Table 2 Catalytic Hydrogenation of Aldehydes with 2. ${ }^{a}$

\begin{tabular}{|c|c|c|c|c|c|c|}
\hline Entry & Substrate & Product & $t(\mathbf{h})$ & Conv. $(\%)^{b}$ & Selectivity $(\%)^{c}$ & TOF $\left(h^{-1}\right)$ \\
\hline 1 & & & 2.5 & 97 & 99:1 (UA:A) & $2040^{d}$ \\
\hline 2 & & & 5 & 38 & 99:1 (UA:A) & 228 \\
\hline 3 & & & 5 & 94 & 97:3 (UA:A) & 564 \\
\hline 4 & & & 5 & $>99$ & $>99$ & 600 \\
\hline 5 & & & 5 & $>99$ & $>99$ & 600 \\
\hline 6 & & & 20 & $>99$ & $>99$ & 150 \\
\hline 7 & & & 5 & 96 & $>99$ & 720 \\
\hline 8 & & & 5 & 98 & $>99$ & 588 \\
\hline
\end{tabular}

${ }^{a}$ Reagents and conditions: $2(0.00125 \mathrm{mmol})$, substrate $(3.75 \mathrm{mmol})$, THF $(0.75 \mathrm{~mL}), 295 \mathrm{~K}, 5$ bar of $\mathrm{H}_{2}{ }^{b}$ Conversions and product identities were determined by ${ }^{1} \mathrm{H}$ NMR spectroscopy (average of two runs). ${ }^{c} U A=$ Unsaturated Alcohol, $A=$ Saturated Alcohol, $A l=$ Saturated Aldehyde. ${ }^{d}$ Maximum TOF.

\section{CONCLUSIONS}

In summary, we have successfully used an Ir-SPO complex to activate dihydrogen under mild conditions. The treatment of the iridium (I) complex with $\mathrm{H}_{2}$ led, via $\mathrm{H}_{2}$ oxidative addition, to the formation of a mixture of one monohydride $\operatorname{Ir}\left((\mathrm{SPO})_{2} \mathrm{H}\right) \mathrm{H}$ (solvent $)_{2} \mathrm{X}$, two diastereomeric dihydrides $\operatorname{Ir}\left((\mathrm{SPO})_{2} \mathrm{H}\right) \mathrm{H}_{2}$ (solvent $)_{2}$, and three bridging dihydride dimers as minor species. Such a process undergoes a high degree of diastereoselectivity, since a thorough characterization of the different iridium (III) hydride complexes by 1D and 2D NMR spectroscopy showed that all monomeric species are homochiral. In addition, the crystal structure of a dinuclear iridium (III) hydride complex was determined by X-Ray Diffraction and discussed. This dimer shows the preferred homochiral coordination for each half of the molecule, with opposite chirality resulting in an inversion center for the dimer.

This catalytic system was highly efficient for the chemoselective hydrogenation of substituted aldehydes, displaying exceptionally high activities and selectivities for a wide variety of 
substrates. For instance, the hydrogenation of cinnamaldehyde proceeded with a TOF of $2040 \mathrm{~h}^{-}$ ${ }^{1}$ and a selectivity of $99 \%$. The catalyst works without the help of an external base or additive presumably through a ligand-metal cooperative mechanism in which the SPO ligand might play a crucial double role, as modifying ligand, and as functional ligand acting as heterolytic activator for dihydrogen. Finally, it is worth noting that with the study reported herein, SPO ligands have shown their merit in homogeneous hydrogenation catalysis, which may inspire the design of new homogeneous SPO-based catalysts that incorporate earth-abundant metals and exhibit similar catalytic properties.

\section{CONFLICTS OF INTEREST}

There are no conflicts of interest to declare.

\section{ACKNOWLEDGEMENTS}

We thank UPS-Toulouse and INSA for financial support. Dr. Israel Cano acknowledges financial support from the European Community through a Marie Skłodowska-Curie Individual Fellowships (IF-EF; Programme/Call: H2020-MSCA-IF-2015; Proposal No: 704710Sdchirnanocat). Prof. P. W. N. M. van Leeuwen thanks the Université Fédérale Toulouse MidiPyrénées for an IDEX Chaire d'Attractivité.

\section{NOTES AND REFERENCES}

1 (a) P. Gallezot and D. Richard, Catal. Rev., 1998, 40, 81-126; (b) P. Mäki-Arvela, J. Hájek, T. Salmi and D. Y. Murzin, Appl. Catal. A-Gen., 2005, 292, 1-49.

2 H. Berke, ChemPhysChem, 2010, 11, 1837-1849.

3 R. H. Crabtree, in The Organometallic Chemistry of the Transition Metals, 5th ed., Wiley-Interscience: Hoboken, NJ, 2009.

4 (a) E. T. Papish, M. P. Magee and J. R. Norton, in Recent Advances in Hydride Chemistry, eds. M. Peruzzini and R. Poli, Elsevier, Amsterdam, 2001, Chapter 2; (b) G. J. Kubas, in Metal Dihydrogen and $\sigma$-Bond Complexes, Kluwer Academic/Plenum Publishers, New York, 2001; (c) Handbook of Homogeneous Hydrogenation, eds. J. G. de Vries, and C. J. Elsevier, Wiley-VCH, Weinheim, 2007.

5 For chemoselective hydrogenation of substituted aldehydes catalyzed by iridium-based complexes, see: (a) W. Strohmeier and H. Steigerwald, J. Organomet. Chem., 1977, 129, 43-46; (b) E. Farnetti, M. Pesce, J. Kaspar, R. Spogliarich and M. Graziani, J. Chem. Soc., Chem. Commun., 1986, 746-747; (c) C. S. Chin, B. Lee and S. C. Park, J. Organomet. Chem., 1990, 393, 131-135; (d) C. S. Chin and B. Lee, J. Chem. Soc., Dalton Trans., 1991, 1323-1327; (e) L. Dahlenburg, K. Herbst and A. Zahl, J. Organomet. Chem., 2000, 616, 19-28; (f) R.-X. Li, X.-J. Li, N.-B. Wong, K.-C. Tin, Z.-Y. Zhou and T. C. W. Mak, J. Mol. Catal. A: Chem., 2002, 178, 181-190; (g) F. López-Linares, G. Agrifoglio, A. Labrador and A. Karam, J. Mol. Catal. A: Chem., 2004, 207, 117-122; (h) X. Wu, C. Corcoran, S. Yang and J. Xiao, 
ChemSusChem, 2008, 1, 71-74; (i) M. G. Manas, J. Graeupner, L. J. Allen, G. E. Dobereiner, K. C. Rippy, N. Hazari and R. H. Crabtree, Organometallics, 2013, 32, 4501-4506.

6 For chemoselective transfer hydrogenation of substituted aldehydes catalyzed by iridium-based complexes, see: X. Wu, J. Liu, X. Li, A. Zanotti-Gerosa, F. Hancock, D. Vinci, J. Ruan and J. Xiao, Angew. Chem. Int. Ed., 2006, 45, 6718-6722.

7 (a) B. F. Machado, H. T. Gomes, P. Serp, P. Kalck and J. L. Faria, ChemCatChem, 2010, 2, 190-197; (b) P. Chen, J.-Q. Lu, G.-Q. Xie, G.-S. Hu, L. Zhu, L.-F. Luo, W.-X. Huang and M.-F. Luo, Appl. Catal. A-Gen., 2012, 433-434, 236-242; (c) H. Rojas, J. L. Martinez, S. Mancipe, G. Borda and P. Reyes, React. Kinet. Mech. Cat., 2012, 106, 445-455; (d) H. Rojas, G. Diaz, J. J. Martinez, C. Castaneda, A. Gomez-Cortes and J. Arenas-Alatorre, J. Mol. Catal. A: Chem., 2012, 363-364, 122-128; (e) M. Tamura, K. Tokonami, Y. Nakagawa and K. Tomishige, Chem. Commun., 2013, 49, 7034-7036; (f) J. Zhao, J. Ni, J. Xu, J. Xu, J. Cen and X. Li, Catal. Commun., 2014, 54, 72-76.

8 (a) M. Consonni, D. Jokic, D. Y. Murzin and R. Touroude, J. Catal., 1999, 188, 165-175; (b) P. Concepcion, A. Corma, J. Silvestre-Albero, V. Franco and J. Y. Chane-Ching, J. Am. Chem. Soc., 2004, 126, 5523; (c) M. Boronat, F. Illas and A. Corma, J. Phys. Chem. A, 2009, 113, 3750-3757; (d) M. Boronat, P. Concepción, A. Corma, J. Phys. Chem. C, 2009, 113, 16772-16784; (e) D. A. Panayotov, S. P. Burrows, J. T. Yates and J. R Morris, J. Phys. Chem. C, 2011, 115, 22400-22408.

9 (a) D. Martin, D. Moraleda, T. Achard, L. Giordano and G. Buono, Chem. Eur. J., 2011, 17, 1272912740; (b) P. Sutra and A. Igau, Coord. Chem. Rev., 2016, 308, 97-116.

10 B. Hoge, S. Neufeind, S. Hettel, W. Wiebe and C. Thösen, J. Organomet. Chem., 2005, 690, 23822387.

11 (a) P. W. N. M. van Leeuwen and C. F. Roobeek, Eur. Pat. Appl., EP 82576, 1983 (Chem. Abstr., 1983, 99, 121813); (b) P. W. N. M. van Leeuwen, C. F. Roobeek, R. L. Wife and J. H. G. Frijns, J. Chem. Soc., Chem. Commun., 1986, 31-33; (c) P. W. N. M. van Leeuwen, C. F. Roobeek, J. H. G. Frijns and A. G. Orpen, Organometallics, 1990, 9, 1211-1222; (d) P. W. N. M. van Leeuwen and C. F. Roobeek, New J. Chem., 1990, 14, 487-493; (e) P. M. Castro, H. Gulyas, J. Benet-Buchholz, C. Bo, Z. Freixa and P. W. N. M. van Leeuwen, Catal. Sci. Technol., 2011, 1, 401-407.

12 See the following for a variety of examples related to hydrogenation via ligand-metal cooperation performed by SPO-based catalysts: (a) X.-b. Jiang, A. J. Minnaard, B. Hessen, B. L. Feringa, A. L. L. Duchateau, J. G. O. Andrien, J. A. F. Boogers and J. G. de Vries, Org. Lett., 2003, 5, 1503-1506; (b) X.b. Jiang, M. van den Berg, A. J. Minnaard, B. L. Feringa and J. G. de Vries, Tetrahedron: Asymmetry, 2004, 15, 2223-2229; (c) N. V. Dubrovina and A. Börner, Angew. Chem. Int. Ed., 2004, 43, 5883-5886; (d) L. Ackermann, Synthesis, 2006, 1557-1571; (e) H. Landert, F. Spindler, A. Wyss, H.-U. Blaser, B. Pugin, Y. Ribourduoille, B. Gschwend, B. Ramalingam and A. Pfaltz, Angew. Chem. Int. Ed., 2010, 49, 6873-6876; (f) T. M. Shaikh, C.-M. Weng and F.-E. Hong, Coord. Chem. Rev., 2012, 256, 771-803; (g) K. Dong, Z. Wang and K. Ding, J. Am. Chem. Soc., 2012, 134, 12474-12477.

13 (a) E. Rafter, T. Gutmann, F. Low, G. Buntkowsky, K. Philippot, B. Chaudret and P. W. N. M. van Leeuwen, Catal. Sci. Technol., 2013, 3, 595-599; (b) I. Cano, A. M. Chapman, A. Urakawa and P. W. N. M. van Leeuwen, J. Am. Chem. Soc., 2014, 136, 2520-2528; (c) I. Cano, M. A. Huertos, A. M. Chapman, 
G. Buntkowsky, T. Gutmann, P. B. Groszewicz and P. W. N. M. van Leeuwen, J. Am. Chem. Soc., 2015, 137, 7718-7727; (d) I. Cano, M. J.-L. Tschan, L. M. Martínez-Prieto, K. Philippot, B. Chaudret and P. W. N. M. van Leeuwen, Catal. Sci. Technol., 2016, 6, 3758-3766; (e) N. Almora-Barrios, I. Cano, P. W. N. M. van Leeuwen and N. Lopez, ACS Catal., 2017, 7, 3949-3954.

14 I. Cano, L. M. Martínez-Prieto, B. Chaudret and P. W. N. M. van Leeuwen, Chem. Eur. J., 2017, 23, 1444-1450.

15 (a) D. M. Roundhill, R. P. Sperline and W. B. Beaulieu, Coord. Chem.Rev., 1978, 26, 263-279; (b) J. A. S. Duncan, D. Hedden, D. M. Roundhill, T. A. Stephenson and M. D. Walkinshaw, Angew. Chem., Int. Ed. Engl., 1982, 21, 452-453; (c) J. A. S. Duncan, T. A. Stephenson, W. B. Beaulieu and D. M. Roundhill, J. Chem. Soc., Dalton Trans., 1983, 1755-1761; (d) J. A. S. Duncan, T. A. Stephenson, M. D. Walkinshaw, D. Heden and D. M. Roundhill, J. Chem. Soc., Dalton Trans., 1984, 801-807; (e) B. Patel, S. J. A. Pope and G. Reid, Polyhedron, 1998, 17, 2345-2351; (f) C. Waloch, J. Wieland, M. Keller and B. Breit, Angew. Chem., Int. Ed., 2007, 46, 3037-3039; (g) B. Breit, in Supramolecular Catalysis, ed. P. W. N. M van Leeuwen, Wiley-VCH Verlag, GmbH Weinheim, Germany, 2008, pp. 29-55; (h) J. Meeuwissen, R. J. Detz, A. J. Sandee, B. de Bruin and J. N. H. Reek, Dalton Trans., 2010, 39, 1929 1931.

16 S. Gruber, M. Neuburger, A. Pfaltz, Organometallics, 2013, 32, 4702-4711.

17 (a) A. Ç. Atesin, S. B. Duckett, C. Flaschenriem, W. W. Brennessel and R. Eisenberg, Inorg. Chem. 2007, 46, 1196-1204; (b) E. P. K. Olsen, T. Singh, P. Harris, P. G. Andersson, and R. Madsen, J. Am. Chem. Soc., 2015, 137, 834-842.

18 F. M. Chadwick, N. Olliff and A. S. Weller, J. Organomet. Chem., 2016, 812, 268-271.

19 (a) G. Robertson and P. Tucker, Aust. J. Chem., 1984, 37, 257-263; (b) C. Bianchini, E. Farnetti, M. Graziani, J. Kaspar and F. Vizza, J. Am. Chem. Soc., 1993, 115, 1753-1759; (c) R. C. Schnabel and D. M. Roddick, Organometallics, 1993, 12, 704-711; (d) R. C. Schnabel, P. S. Carroll and D. M. Roddick, Organometallics, 1996, 15, 655-662; (e) J. D. Feldman, J. C. Peters and T. D. Tilley, Organometallics, 2002, 21, 4050-4064; ( $f$ ) A. Choualeb, A. J. Lough and D. G. Gusev, Organometallics, 2007, 26, 5224 5229; (g) R. Peloso, R. Pattacini, C. S. J. Cazin and P. Braunstein, Inorg. Chem., 2009, 48, 11415-11424; (h) A. Franzke, F. Voss and A. Pfaltz, Tetrahedron, 2011, 67, 4358-4363; (i) A. J. Pontiggia, A. B. Chaplin and A. S. Weller, J. Organomet. Chem., 2011, 696, 2870-2876.

20 D. V. Naik, G. J. Palenik, S. Jacobson and A. J. Carty, J. Am. Chem. Soc., 1974, 96, 2286-2288.

21 A heterolytic cleavage in which the $\mathrm{H}_{2}$ molecule is cleaved by a metal-ligand cooperative mechanism could occur. The monoanionic bidentate ligand acts as heterolytic activator for dihydrogen and takes a $\mathrm{H}^{+}$ from $\mathrm{H}_{2}$, leaving a $\mathrm{H}^{-}$bound to the metal center. In this scenario, a referee suggested that the monoanionic ligand would be converted in two neutral hydroxyphosphine ligands and a monohydride $\operatorname{Ir}(\mathrm{I})$ complex would be formed. Subsequently, fast migration of one $\mathrm{H}^{+}$regenerates the monoanionic bidentate ligand and leads to the formation of an iridium (III) dihydride complex.

22 N. Herron and D. L. Thorn, Adv. Mat., 1998, 10, 1173-1184.

23 See the following for a variety of examples related to the selective hydrogenation and transfer hydrogenation of alkynyl ketones catalyzed by Ru-based complexes: (a) T. Ohkuma, H. Ooka, T. Ikariya, 
and R. Noyori, J. Am. Chem. Soc., 1995, 117, 10417-10418; (b) K. Matsumura, S. Hashiguchi, T. Ikariya and R. Noyori, J. Am. Chem. Soc., 1997, 119, 8738-8739. 